\title{
Interference and facilitation in overt speech production investigated with event-related potentials
}

Citation for published version (APA):

Hirschfeld, G., Jansma-Schmitt, B. M., Bolte, J., \& Zwitserlood, P. (2008). Interference and facilitation in overt speech production investigated with event-related potentials. Neuroreport, 19(12), 1227-1230. https://doi.org/10.1097/WNR.0b013e328309ecd1

Document status and date:

Published: 01/01/2008

DOI:

10.1097/WNR.0b013e328309ecd1

Document Version:

Publisher's PDF, also known as Version of record

Document license:

Taverne

Please check the document version of this publication:

- A submitted manuscript is the version of the article upon submission and before peer-review. There can be important differences between the submitted version and the official published version of record.

People interested in the research are advised to contact the author for the final version of the publication, or visit the DOI to the publisher's website.

- The final author version and the galley proof are versions of the publication after peer review.

- The final published version features the final layout of the paper including the volume, issue and page numbers.

Link to publication

\footnotetext{
General rights rights.

- You may freely distribute the URL identifying the publication in the public portal. please follow below link for the End User Agreement:

www.umlib.nl/taverne-license

Take down policy

If you believe that this document breaches copyright please contact us at:

repository@maastrichtuniversity.nl

providing details and we will investigate your claim.
}

Copyright and moral rights for the publications made accessible in the public portal are retained by the authors and/or other copyright owners and it is a condition of accessing publications that users recognise and abide by the legal requirements associated with these

- Users may download and print one copy of any publication from the public portal for the purpose of private study or research.

- You may not further distribute the material or use it for any profit-making activity or commercial gain

If the publication is distributed under the terms of Article $25 \mathrm{fa}$ of the Dutch Copyright Act, indicated by the "Taverne" license above, 


\title{
Interference and facilitation in overt speech production investigated with event-related potentials
}

\author{
Gerrit Hirschfeld ${ }^{\mathrm{a}}$, Bernadette Jansma ${ }^{\mathrm{b}}$, Jens Bölte ${ }^{\mathrm{a}}$ and Pienie Zwitserlood ${ }^{\mathrm{a}}$

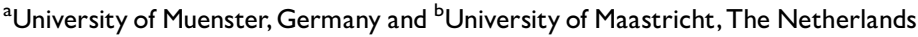 \\ Correspondence to Gerrit Hirschfeld, Psychologisches Institut II, Westfälische Wilhelms-Universität Münster, Fliednerstraße 2l, \\ 48149 Münster, Germany \\ Tel: + 4925 8331378; fax: + 49251 8334104; e-mail: gerrit.hirschfeld@uni-muenster.de
}

Received 30 April 2008; accepted 23 May 2008

\begin{abstract}
We report an event-related potential study investigating the neural basis of interference and facilitation in the picture-word interference paradigm with immediate overt naming. We used the high temporal resolution of the electrophysiological response to dissociate general and specific interference processes, by comparing unrelated word distractors to nonlinguistic (a row of Xs), surface feature denoting, and category member distractors. Our results first indicate that the increased naming latencies for linguistic relative to nonlinguistic distractors are because of general conflict-monitoring processes, associated with early event-related
\end{abstract}

potential effects ( $120-220 \mathrm{~ms}$ ) and increased activity in the anterior cingulate cortex. Next, distractors specifying a surface feature of the picture seem to facilitate its identification within the same time window, which involves widespread networks. Finally, nonlinguistic and surface feature distractors also reduced the $\mathrm{N} 400$ amplitude, relative to unrelated word distractors. Taken together our results support the view that several distinct processes give rise to the reaction time results often observed in picture naming. NeuroReport 19:1227-1230 (c) 2008 Wolters Kluwer Health | Lippincott Williams \& Wilkins.

Keywords: event-related potentials, overt naming, semantics, speech production

\section{Introduction}

Speaking is a cognitive ability unique to humans. One of the most fascinating aspects of this ability is the ease and effortlessness with which we are able to select from among the many lexical items in our brain the one we are going to utter next. Accordingly, lexical competition for selection, and the resulting interference, are central to most models of language production [1]. Such effects can be observed when participants name target pictures in the presence of either written or spoken distractors. In this picture word interference (PWI) scenario, word distractors cause general interference, prolonging naming latencies, and increasing error rates compared with nonlinguistic distractors [2].

In addition, semantically related distractors cause specific interference and prolong reaction times (RTs) more than unrelated words. Semantically related words receive input from the distractor and from the target via spreading activation. Thus, they are more potent competitors to the target than unrelated words, which are only activated by the distractor. It has recently been questioned whether the semantic interference effect generalizes to all types of semantically related distractors $[3,4]$. Although, distractors from the same semantic category as the target picture cause interference, words denoting its surface features, place information, or parts lead to facilitation [5]. Current theories of speech production attribute this to enhanced activation of the target concept, which outweighs both the general and the semantic interference effect [6].
The aim of this study was to use the high temporal resolution of event-related potentials (ERP) to track the time course of general and specific interference in the PWI, by comparing an (a) unrelated word condition to three experimental conditions: (b) nonlinguistic (a row of Xs), (c) surface feature, and (d) category member distractors. Earlier neurocognitive studies used delayed naming [7] or a combination of self-generated primes and auditory distractors [8] to investigate the neural processes underlying speech planning. These studies consistently revealed reductions of the N400 amplitude for related words compared with unrelated words. Considering that lexical selection is completed about $250 \mathrm{~ms}$ after picture onset [1], the functional relevance of these effects is unclear. A magnetoencephalography (MEG) study with direct naming indicates a much earlier $(<200 \mathrm{~ms})$ onset of semantic interference in a blocked naming paradigm [9].

On the basis of the above observations, we hypothesized overall differences between linguistic and nonlinguistic distractors. We expected longer naming latencies with unrelated word distractors than with nonlinguistic distractors, and early differences in the ERPs between those conditions. We also expected more subtle effects of the different types of linguistic distractors, that is, interference for category members and facilitation for surface feature distractors. These differences in semantic relations may also be reflected in modulations of early ERP components and the N400. 


\section{Methods}

Sixteen (one male) right-handed native speakers of German (age $18-25$ years) participated in a $1 \mathrm{~h}$ recording session. All had normal or corrected to normal vision. Participants were either paid $15 €$ or received course credits. All gave informed consent according to standards of the ethical board of the University of Maastricht.

Experimental trials consisted of to-be-named target pictures and written distractors. Each trial began with the presentation of a fixation cross in the middle of the screen. After a randomized interval of $150-350 \mathrm{~ms}$, the distractor appeared in the middle of the screen, in Helvetica 16 point, white against a black background. After $150 \mathrm{~ms}$ (stimulus onset asynchrony -150) the picture, white on black, appeared. Distractor and picture were visible for $400 \mathrm{~ms}$. Participants were asked to name the picture as fast as possible. Response latencies were collected via a voice key from picture onset until time out $(3000 \mathrm{~ms})$ and scored for correctness. Intertrial interval was $3500 \mathrm{~ms}$.

Fifty line drawings of concrete objects, scaled to a height or width of $5 \mathrm{~cm}$ ( $4.5^{\circ}$ of visual angle), were used as test pictures. Each picture (e.g. of a dog), appeared in four distractor conditions, labeled (a) unrelated word (e.g. Blume, flower), (b) nonlinguistic (row of Xs), (c) surface feature (e.g. Fell, fur), and (d) category member (e.g. Katze, cat). We added 113 filler pictures, all preceded by unrelated words, so that only $25 \%$ of the trials were related.

The materials were distributed over five blocks of 80 trials, separated by four short breaks. Targets were never repeated within a block. In each block, half of the trials were fillers and half were experimental trials. The order of items within each block were randomized separately for each participant. Each participant received all blocks twice, with order being balanced across participants. Participants were asked to rest their arms and hands on the elbow rest of the armchair and instructed not to blink or move their eyes. Participants read a booklet with the correct target names before the experiment to ensure consistent target picture naming.

ERPs were recorded from the scalp using 29 electrodes mounted in an electro cap with a left mastoid online reference and referenced offline to the mean of the amplitude at the two mastoid processes. Blinks and vertical eye movements were recorded with bipolar electrodes placed on the right and the left canthus and the upper and lower orbital ridge, to allow for later offline rejection, on the basis of an amplitude criterion $( \pm 75 \mu \mathrm{V}$ threshold). All electrode impedances were kept below $5 \mathrm{k} \Omega$.

Electrophysiological signals were amplified with Neuroscan Synamps with a bandpass filter of $0.05-50 \mathrm{~Hz}$, and digitized at a rate of $250 \mathrm{~Hz}$. ERPs were calculated timelocked to the onset of the target picture and comprised a $700-\mathrm{ms}$ period $(-100-600 \mathrm{~ms})$. Waveforms were quantified by mean amplitude measures that were entered into analysis of variance statistics.

\section{Results}

Electroencephalogram (EEG) data of two participants were excluded from further analysis because of high-frequency noise on all channels. Overall, $17.5 \%$ of the trials had to be excluded because of eye blinks or wrong answers. The number of rejections did not differ reliably between conditions. The average ERP was calculated for all electrode

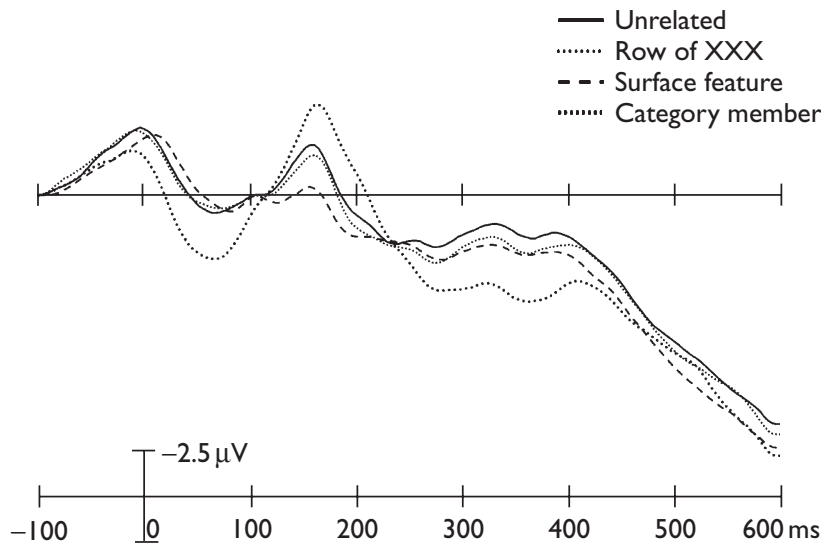

Fig. I Grand averages for the distractor types at electrode Cz.

sites, per participant and condition. Grand averages for the experimental conditions are shown in Fig. 1.

\section{Behavioral findings}

Wrong answers, disfluencies, triggering of the voice key by nonspeech sounds, RTs shorter than $200 \mathrm{~ms}$ and longer than $1500 \mathrm{~ms}$ were omitted from statistical analysis. The overall error rate was $4.0 \%$. The naming latencies calculated over participants for the experimental conditions were submitted to by-participant repeated measurement analyses of variance, with distractor-type as within-participants factor. Degrees of freedom were adjusted with the conservative lower bound procedure. Planned comparisons against the unrelated word condition with $t$-tests (onetailed), were used to confirm the predicted direction of each effect.

The results showed a significant main effect for distractortype $[\mathrm{F}(1,15)=21.979, P<0.001]$. Compared with unrelated words ( $805 \mathrm{~ms})$, naming was $25 \mathrm{~ms}$ faster with nonlinguistic distractors $(P<0.001), 24 \mathrm{~ms}$ faster with surface features $(P<0.001)$, and category members slowed down picture naming by $14 \mathrm{~ms}(P=0.036)$. This pattern corroborates earlier findings [4]. Note that feature-denoting distractors counteracted the general interference produced by linguistic distractors.

\section{Electrophysiological findings}

The ERP data were analyzed on the basis of visual inspection of variation in standard components. As can be seen in Fig. 1, the ERP waves differ between the unrelated word condition and the other conditions in several time windows.

Repeated-measures analysis of variances (ANOVAs) for mean ERP amplitudes were carried out for the critical time windows with the factors distractor-type (surface feature, category member, nonlinguistic, unrelated word) and electrodes. Planned pairwise comparisons were calculated to evaluate differences between conditions whenever a main effect became significant. To investigate the scalp topography of the effects in more detail, we split the electrodes into nine groups along the factors frontal versus parietal (frontal, medial, parietal) and hemisphere (left, middle, right). The Greenhouse-Geisser correction was used to adjust for the violation of the sphericity assumption. 
Zero to hundred milliseconds after picture onset

In this time window, the nonlinguistic distractors were accompanied by more positive going signals than all other conditions. The omnibus ANOVA (with distractor-type and electrodes as factor) revealed a significant main effect of distractor-type $[\mathrm{F}(3,39)=13.107, P<0.001]$ and electrodes $[\mathrm{F}(28,364)=4.211, P<0.037]$ and a significant interaction $[\mathrm{F}(84,1092)=5.489, \quad P<0.001]$. Pairwise comparisons revealed that the nonlinguistic condition was more positive than all linguistic conditions (all $P_{\mathrm{S}}<0.01$ ). The topographic analysis indicates that this effect is located in the left hemisphere, and most pronounced at parietal sites. An ANOVA with the unrelated word and nonlinguistic distractor conditions only, and the factors hemisphere and front versus back, revealed significant interactions between distractor-type and hemisphere $[\mathrm{F}(2,26)=18.754, P<0.001]$ and between distractor-type and front versus back $[F(2,26)=4.420, P=0.049]$. No significant differences were observed between the linguistic conditions (all $P \mathrm{~s}<0.15$ ).

\section{One hundred and twenty to two hundred and} twenty milliseconds (early object recognition)

All word distractors induced more positive signals than nonlinguistic distractors. An ANOVA with distractortype and electrode as factors showed significant effects for distractor-type $[\mathrm{F}(3,39)=10.374, P<0.001]$, electrode $[\mathrm{F}(28,364)=3.413, P=0.057]$, and the distractor-type-electrode interaction $[F(84,1092)=9.297, P<0.001]$. Nonlinguistic distractors were more negative than all word conditions (all $P_{\mathrm{s}}<0.02$ ). The difference map between the nonlinguistic and the unrelated word condition shows that the effect is more frontal and stronger over the right hemisphere. For these two distractor conditions, there were significant interactions between distractor-type and hemisphere $[\mathrm{F}(2,26)=5.105, P=0.02]$ and distractor-type and front versus back $[\mathrm{F}(2,26)=32.443, P<0.001]$.

Within word distractors, the surface features were less negative than both category members $(P=0.07)$ and unrelated words $(P=0.01)$, which did not differ $(P>0.3)$. The difference between surface features and the two other linguistic conditions was widely distributed. The ANOVA did not reveal any significant interactions between the hemisphere or front versus back factors and condition $\left(P_{\mathrm{S}}>0.15\right)$.

\section{Two hundred and fifty to four hundred and fifty milliseconds (N400 time window)}

In the N400 time window, there were significant main effects of distractor-type $[\mathrm{F}(3,39)=5.560, P=0.007]$, electrode $[\mathrm{F}(28,364)=7.736, P=0.004]$, and a significant interaction $[\mathrm{F}(84,1092)=2.809, P=0.015]$. The nonlinguistic distractors were less negative than all word distractors (all $P_{\mathrm{S}}<0.07$ ). This effect seems to be mainly left lateralized, as the ANOVA for this contrast showed a significant interaction between distractor-type and hemisphere $[\mathrm{F}(2,26)=7.928$, $P=0.003$ ]. In addition, a trend for surface features to be less negative than unrelated words $(P=0.116)$ was present. Again, there were no differences between the unrelated word and category member condition.

\section{Discussion}

We used EEG recordings with overt naming in a pictureword interference paradigm to investigate the time course of speech planning. We replicated earlier behavioral findings about the effects of four different types of distractors (nonlinguistic, surface features, category members, and unrelated words) on picture naming. Furthermore, we found reliable ERP differences between these conditions, which offer important information about underlying processes [10]. First, linguistic and nonlinguistic distractors evoked different brain activity. Second, the kind of semantic relation between distractor and target modulated both RTs and electrophysiological response. We will discuss each of these results in turn.

\section{General interference for linguistic distractors}

As expected, we found behavioral interference when comparing word distractors to the rows of XXX. The ERPs for these conditions differed in all time windows (Fig. 1). The effect in the earliest time window $(0-100 \mathrm{~ms})$ is most likely the recognition potential (RP), indexing the processing of the distractor as either a meaningful string of letters (word) or not, which extends beyond target picture onset. As the distractors appeared $150 \mathrm{~ms}$ before picture onset, the activity observed at picture onset is within the peak of the RP (between 200 and $250 \mathrm{~ms}$ after stimulus onset). Usually, the RP amplitude is largest for meaningful stimuli, whereas stimuli without meaning have smaller amplitudes [11]. This is exactly what is observed here.

The second frontal effect, between 120 and $220 \mathrm{~ms}$, also concerned a difference between linguistic and nonlinguistic distractors, and it seems to indicate a modulation of activation in the anterior cingulate. An earlier functional MRI study with PWI, contrasting nonlinguistic and category member distractors, found activation in this area [12]. The most plausible interpretation is in terms of a general conflict monitoring process [13], which is triggered more strongly by words than by nonlinguistic distractors, as only the former have to be suppressed for target naming.

The second effect within this time window, the special impact of surface feature distractors, is discussed below. Interestingly, the earlier MEG study [9] found a leftlateralized effect when comparing naming in same category blocks to unrelated blocks in this time window. This suggests that the general and the specific interference effects are mediated by different neural populations.

Finally, we again found a robust difference between linguistic and nonlinguistic distractors in the N400 time window [14]. As expected from the studies on language comprehension [15] and on production with delayed naming [7,8], pictures which did not fit the context established by the preceding distractor evoked the largest negative responses. The fact that nonlinguistic stimuli evoke smaller N400 amplitudes than linguistic distractors indicates that integration is probably not even attempted with these stimuli.

\section{Specific semantic effects}

The differences between the different kinds of linguistic stimuli were more subtle. We replicated behavioral interference for category members, and facilitation for surface features. As the earlier EEG studies [7,8], we did not find any early differences between the category member and unrelated word conditions, which is in contrast to the deflection reported in the MEG study [9]. More research is needed to establish whether this is a function of the different electrophysiological methods, or of the general design of the studies. 
Most interestingly, we observed a very early (120-220 ms after picture onset) effect of surface feature distractors on the processing of target pictures. In this time window, surface features elicited a less negative going deflection than unrelated words. Although it has been known for more than a decade that the visual system can differentiate between categories of pictures after as little as $120 \mathrm{~ms}$ [16], it is a fairly new finding that linguistic cues can influence these early stages of object processing. Until now, such early influences on the electrophysiological responses to target pictures involved a comparison of the presentation of their correct name with the name of a different object [17]. Another line of research showed that knowledge about formerly unknown objects modulates the amplitude of the P1 and N400 to pictures [18]. Our data indicate that a surface feature denoting word can influence visual processing of objects in a similar top-down manner. As a consequence, such words speed up object identification in the PWI paradigm [6] resulting in similar naming latencies as with nonlinguistic distractors. More research is needed to investigate exactly how language processing is related to perceptual mechanisms [19].

\section{Conclusion}

The results of this study indicate that different neural processes give rise to the reaction time results in PWI. Nonlinguistic distractors decrease naming latencies because a general conflict monitoring system, presumably the anterior cingulate cortex, is being modulated. Surface feature distractors apparently not only speed-up language processing, but also affect picture identification. This demonstrates that ERPs are an important source of information about the time course of the processes underlying general interference and facilitation in speech production.

\section{Acknowledgement}

The authors thank Annett Jorschick for the help in conducting this experiment.

\section{References}

1. Levelt WJM, Roelofs A, Meyer AS. A theory of lexical access in speech production. Behav Brain Sci 1999; 22:1-75.
2. Schriefers H, Meyer AS, Levelt WJM. Exploring the time course of lexical access in language production-picture-word interference studies. J Memory Language 1990; 29:86-102.

3. Alario FX, Segui J, Ferrand L. Semantic and associative priming in picture naming. Q J Exp Psychol A 2000; 53:741-764.

4. Bölte J, Jorschick A, Zwitserlood P. Reading yellow speeds up naming a picture of a banana: facilitation and inhibition in picture-word interference. In: Schmalhofer F, Young R, editors. Proceedings European cognitive science conference. Mawah, NJ: LEA; 2003. pp. 55-60.

5. Jorschick A, Boelte J, Katzenburg M, Zwitserlood P. Three types of semantic associations in the PWI [Bild-Wort-Interferenz ParadigmaDrei Assoziationstypen unter die Lupe genommen]. In: Lange KW, Bäuml K-H, Greenlee MW, Hammerl M, Zimmer A, editors. TEAP 2005. Regensburg: Lengerich: Pabst Science Publishers; 2005.

6. Kuipers J, La Heij W, Costa A. A further look at semantic context effects in language production: the role of response congruency. Lang Cogn Process 2006; 21:892-919.

7. Greenham SL, Stelmack RM, Campbell KB. Effects of attention and semantic relation on event-related potentials in a picture-word naming task. Biol Psychol 2000; 55:79-104.

8. Jescheniak JRD, Schriefers H, Garrett MF, Friederici AD. Exploring the activation of semantic and phonological codes during speech planning with event-related brain potentials. J Cogn Neurosci 2002; 14: 951-964.

9. Maess B, Friederici A, Damian M, Meyer A, Levelt W. Semantic category interference in overt picture naming: sharpening current density localization by PCA. J Cogn Neurosci 2002; 14:455-462.

10. Liotti M, Woldorff MG, Perez R, Mayberg HS. An ERP study of the temporal course of the Stroop color-word interference effect. Neuropsychologia 2000; 38:701-711.

11. Martin-Loeches M. The gate for reading: reflections on the recognition potential. Brain Res Rev 2007; 53:89-97.

12. De Zubicaray G, Wilson S, McMahon K, Muthiah S. The semantic interference effect in the picture-word paradigm: an event-related fMRI study employing overt responses. Hum Brain Mapp 2001; 14:218-227.

13. Barch D, Braver T, Sabb F, Noll D. Anterior cingulate and the monitoring of response conflict: evidence from an fMRI study of overt verb generation. J Cogn Neurosci 2000; 12:298-309.

14. Kutas M, Hillyard SA. Reading senseless sentences-brain potentials reflect semantic incongruity. Science 1980; 207:203-205.

15. Kutas M, Federmeier KD. Electrophysiology reveals semantic memory use in language comprehension. Trends Cogn Sci 2000; 4:463-470.

16. Thorpe S, Fize D, Marlot C. Speed of processing in the human visual system. Nature 1996; 381:520-522.

17. Johnson JS, Olshausen BA. The earliest EEG signatures of object recognition in a cued-target task are postsensory. J Vis 2005; 5:399-312.

18. Abdel Rahman R, Sommer W. Seeing what we know and understand: how knowledge shapes perception. Psychonomic Bulletin E Review 2008; [accepted].

19. Barsalou LW. Perceptual symbol systems. Behav Brain Sci 1999; 22: 577-660. 